\title{
Nanoparticle Surface Coverage Controls the Speciation of Electrochemically Generated Chlorine
}

Pitchnaree Kraikaew, ${ }^{a}$ Eden E. L. Tanner, ${ }^{\text {b }}$ Stanislav V. Sokolov, ${ }^{b}$ Christopher Batchelor-McAuley, ${ }^{\mathrm{b}}$ Jennifer Holter, ${ }^{\mathrm{c}}$ Neil P. Young, ${ }^{\mathrm{c}}$ and Richard G. Compton ${ }^{*} \mathrm{~b}$

a Department of Chemistry, Faculty of Science, Mahidol University, Rama VI Road, Ratchathewi, Bangkok 10400, Thailand

${ }^{b}$ Department of Chemistry, Physical and Theoretical Chemistry Laboratory, Oxford University, South Parks Road, Oxford OX1 3QZ, United Kingdom

${ }^{c}$ Department of Materials, University of Oxford, OX1 3PH, United Kingdom

Corresponding Author

*E-mail: richard.compton@chem.ox.ac.uk. Phone: +44(0) 1865275957.

Fax: +44 (0) 1865275410. 


\begin{abstract}
Cyclic voltammetry is used to investigate the oxidation of chloride on platinum nanoparticles. The electrochemical response of the nanoparticles dropcast on to a glassy carbon electrode is compared to that recorded at a platinum macroelectrode. The use of 'nano' and 'macro' scale Pt reveals different ratios of the electrochemically formed products, chlorine $\left(\mathrm{Cl}_{2}\right)$ and the trichloride $\left(\mathrm{Cl}_{3}{ }^{-}\right)$anion. This difference in the speciation is attributed to the chloride oxidation being a surface reaction limited process. For the situation in which there are a limited number of active sites available on the electrode due to low nanoparticle surface coverages, the sub-diffusion limited currents result in higher chloride concentrations adjacent to the electrochemical interface. This excess chloride at the interface leads to the formation of the trichloride anion. The effect of surface oxide formation towards the chloride oxidation is also examined on both electrodes. Formation of platinum oxide serves to inhibit the rate of chloride oxidation.
\end{abstract}

\title{
Introduction
}

Inner-sphere redox reactions ${ }^{1}$ are a hugely important class of interfacial processes from fundamental, $^{2,3}$ biological, $^{4,5}$ and industrial ${ }^{6,7}$ viewpoints. Much remains unknown about even the most well studied systems, such as hydrogen evolution ${ }^{8,9}$ and oxygen reduction. ${ }^{10,11}$ One distinctive voltammetric feature of such reactions is the occurrence of surface reaction limited currents. ${ }^{12}$ Such reaction limited currents occur under conditions of relatively high mass-transport and when the rate determining step is a chemical processes not involving the transfer of electrons to or from the electrode. The voltammetry of chloride oxidation is an archetypal example of a reaction which may under certain conditions exhibit such reaction limited responses. ${ }^{13}$ One of the first mechanistic studies into chlorine evolution at bulk platinum was conducted by Chang and Wick who evidenced 
the oxidation process through investigation of the experimentally recorded Tafel slopes. ${ }^{14}$ The reduction of $\mathrm{Cl}_{2}$ was also examined by Frumkin and Tedorradze. ${ }^{15}$ The mechanism of chloride oxidation on Pt macroelectrode has been previously reported. ${ }^{16-20}$ The following mechanism shows $\mathrm{Cl}_{2}$ evolution reaction on noble metal surfaces, where $\mathrm{M}$ is an active site and $\mathrm{Cl}$ is discharged on the electrode surface: ${ }^{13}$

$$
\begin{aligned}
& \mathrm{Cl}^{-}+\mathrm{M} \leftrightarrows \mathrm{MCl}^{-} \text {ads }+\mathrm{e}^{-} \\
& 2 \mathrm{MCl}^{\cdot} \text { ads } \rightarrow 2 \mathrm{M}+\mathrm{Cl}_{2}
\end{aligned}
$$

Moreover, the $\mathrm{Cl}_{2}$ generation process is known to involve competition between the formation of oxide species and $\mathrm{Cl}^{-18,21}$ The growth of oxide film can occur concomitantly with $\mathrm{Cl}_{2}$ evolution. Experimentally at high overpotentials, and in the cases of few available active sites on an electrode surface, the second step (equation 2) may be rate determining. Under such cases at high overpotentials a steady-state but non-diffusion limited reaction rate is observed. Conversely, if a relative abundance of active sites exist, as is found with bulk Pt, diffusion of the $\mathrm{Cl}^{-}$to the electrode may be the rate determining step.

Platinum nanoparticles (PtNPs) have been utilised in a number of technological applications including in arsenic detection, glucose sensors based on a PtNPs/polyaniline hydrogel, and PtNPs supported on ionic liquid-modified magnetic nanoparticles for selective hydrogenation catalysts. ${ }^{22-24}$ Moreover, platinum based electrocatalysts are used frequently in the manufacture of low temperature fuel cells, particularly polymer electrolyte membrane fuel cells (PEM). ${ }^{25,26} \mathrm{Pt}$ performs better than all other catalysts in terms of its high activity, selectivity, and stability, which results in Pt currently being a so-far unsurpassed catalyst for hydrogen oxidation reaction (HOR) and oxygen reduction reaction (ORR) in a polymer electrolyte membrane fuel cell (PEMFC). ${ }^{27}$ However, cost reduction is required for commercial use. ${ }^{28}$ The use of nano-Pt based supporting materials for 
fuel cell applications is one route by which costs may be minimised. ${ }^{29-31}$ However, the decrease in Pt stability by chloride absorption in PEMFC is still a serious concern. Furthermore, chloride may contaminate the fuel cell by introduction to the cell through airborne salts or through the catalyst synthetic process (hexachloroplatinate) which promotes platinum corrosion, ${ }^{32}$ particularly under potential cycling. ${ }^{33}$

Stimulated by the diverse uses for nano platinum, significant efforts have been undertaken to try and experimentally elucidate any altered reactivity that may be observed with the use of 'new' nano materials. Importantly, the catalytic properties of these particles are often studied under environments that differ markedly from the conditions under which they will be used industrially (such as within a fuel cell). This work seeks to study the oxidation of chlorine at both bulk and nano platinum. The speciation associated with the oxidation process, as evidenced by the relative ratios of the reductive peak currents differs significantly between the use of the 'nano' and 'bulk' material. However, these observed discrepancies in the voltammetric response of these two materials are not a result of any altered chemistry associated with the nanoparticulate surface but will be shown to arise solely from the altered mass-transport regime experienced by the nanoparticles. This work ultimately highlights how when interpreting data relating to reactions at nanoparticulate surfaces, the local mass-transport regime must be considered.

\section{Experimental}

Potassium chloride $(\mathrm{KCl}, \geq 99.0 \%)$ was purchased from Sigma Aldrich, and used as received. The $0.1 \mathrm{M} \mathrm{KCl}$ solution was prepared using Milli-Q water (resistivity of $18.2 \mathrm{M} \Omega \mathrm{cm}$ at $25^{\circ} \mathrm{C}$ ) and degassed by bubbling with $\mathrm{N}_{2}$ for 15 minutes. Citrate-capped platinum nanoparticles (average radius of $24.3 \pm 1.6 \mathrm{~nm}$, nanoComposix, San Diego, USA) were used as received and sized by Transmission Electron Microscopy (TEM) as shown in Fig 1. The imaging reveals a cluster structure, where the $c a$. $50 \mathrm{~nm}$ (diameter) nanoparticles are composed ca. 740 smaller, ca. $5 \mathrm{~nm}$ particles. 
All electrochemical experiments were performed at $25{ }^{\circ} \mathrm{C}$ using a $\mu$ Autolab type III potentiostat (Metrohm, Netherlands) with a temperature controlled Faraday cage to minimize electrochemical noise. An $\alpha$ value, which denotes at what point in the staircase the current is measured, of 0.3 and a step size of $0.002 \mathrm{~V}$ was employed. ${ }^{34} \mathrm{~A}$ three-electrode configuration was used in this work. A saturated calomel electrode (SCE) was used as a reference, a platinum wire was used a counter electrode, and working electrodes consisted of a platinum macroelectrode $(0.83 \mathrm{~mm}$ radius) and a platinum nanoparticle modified glassy carbon electrode (PtNPs-GCE). The glassy carbon electrode (1.53 $\mathrm{mm}$ radius) was modified by dropcasting from a $60 \mathrm{pM}$ solution of platinum nanoparticles. The working electrodes were polished on felt pads (Buehler, IL, USA) with decreasing size of alumina powder $(1 \mu \mathrm{M}, 0.3 \mu \mathrm{M}, 0.05 \mu \mathrm{M})$ before and between each experiment. The electrode surface was characterised using Scanning Electron Microscopy (SEM) with an accelerating energy of $5.0 \mathrm{kV}$. Two samples were prepared by dropcasting Pt nanoparticles on glassy carbon plates. The first was dried and imaged as is, whilst the second was used to record multiple cyclic voltammograms before imaging.

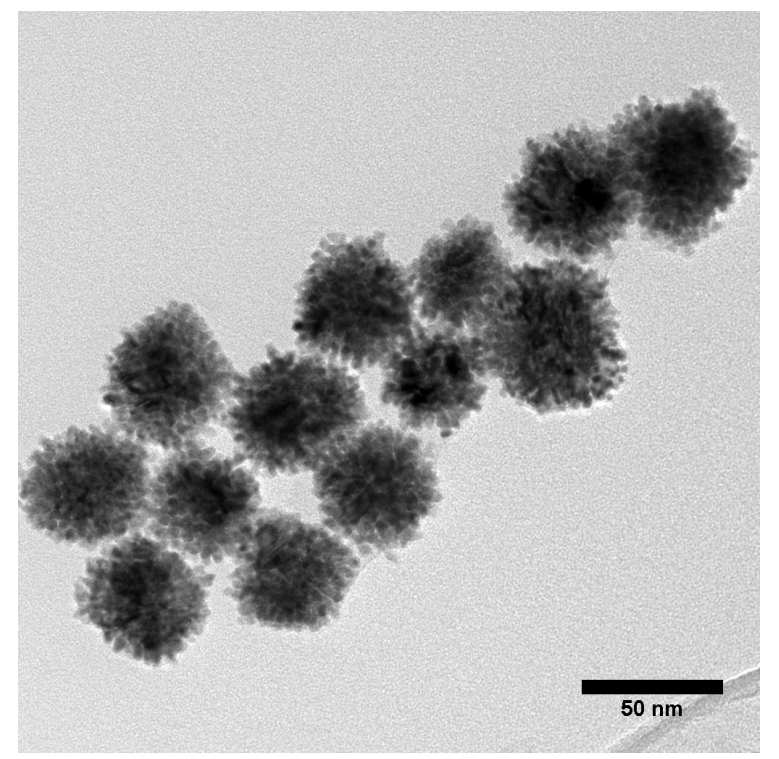

Fig. 1 TEM images of Pt nanoparticles with average radius of $24.3 \pm 1.6 \mathrm{~nm}$. 


\section{Results and Discussion}

This work uses cyclic voltammetry to explore the different electrochemical responses of platinum towards chloride oxidation - first on a platinum macroelectrode and second on dropcast platinum nanoparticles on a glassy carbon electrode. The use of nano-platinum results in different product ratios being observed as compared to a Pt macroelectrode.

Cyclic voltammetry (CV) was first performed on a platinum macroelectrode of $0.83 \mathrm{~mm}$ radius in $0.5 \mathrm{M} \mathrm{KNO}_{3} / 0.1 \mathrm{M} \mathrm{KCl}$ solution. The potential was swept from 0.0 to $1.5 \mathrm{~V}$ vs. SCE at a scan rate of $50 \mathrm{mVs}^{-1}$ (Fig. 2 a). An oxidative peak is observed at ca. $1.3 \mathrm{~V}$ vs SCE, which is ascribed to the oxidation of the solution phase chloride. Successive scans resulted in the peak current decreasing and, after eight scans, the response was found to stabilize. Conversely, use of the same experimental setup but with the voltammogram recorded over the range of -0.5 to $+1.5 \mathrm{~V}$ vs. SCE (Fig. 2 b) results in the oxidative peak current increasing and stabilizing after seven scans at a maximum value of 526 $\mu \mathrm{A}$.

Overall, the oxidation of chloride to chlorine is given by the reaction below:

$$
2 \mathrm{Cl}^{-} \leftrightarrows \mathrm{Cl}_{2}+2 \mathrm{e}^{-}
$$

The stoichiometry of this reaction is non-unity, consequently under a linear diffusion regime the reversible and mass-transported limited voltammetric response is given by the suitably modified version of the Randles-Sevčik equation, as given below: ${ }^{35}$

$$
I_{\text {peak }}=0.1766 \times 2 F A c \sqrt{\frac{2 v F D}{R T}} \quad \text { at } 298 \mathrm{~K}
$$


where $I_{\text {peak }}$ is the peak current (A), $A$ is the area of the platinum macroelectrode $\left(\mathrm{m}^{2}\right), D$ is the diffusion coefficient $\left(\mathrm{m}^{2} \mathrm{~s}^{-1}\right), c$ is the bulk concentration $\left(\mathrm{mol} \mathrm{m} \mathrm{m}^{-3}\right), v$ is the scan rate $\left(\mathrm{V} \mathrm{s}^{-1}\right), F$ is the Faraday constant $\left(\mathrm{Cmol}^{-1}\right)$, and $R$ is the universal gas constant $\left(\mathrm{JK}^{-1} \mathrm{~mol}^{-1}\right)$. This form of the RandlesSevčik equation accounts for the change in the voltammetric waveshape at the fully reversible limit, associated with the altered stoichiometry of the reaction. Equation 3 was then used to calculate the diffusion coefficient for chloride, giving $D_{c l}=1.3 \pm 0.5 \times 10^{-9} \mathrm{~m}^{2} \mathrm{~s}^{-1}$. The consistency of this value with the literature (of $1.8 \times 10^{-9} \mathrm{~m}^{2} \mathrm{~s}^{-1}$, in the absence of the additional supporting electrolyte) ${ }^{36}$ confirms that it is likely that upon cycling of the platinum electrode between -0.5 and $1.5 \mathrm{~V}$ the voltammetric response increases towards the diffusional limit.
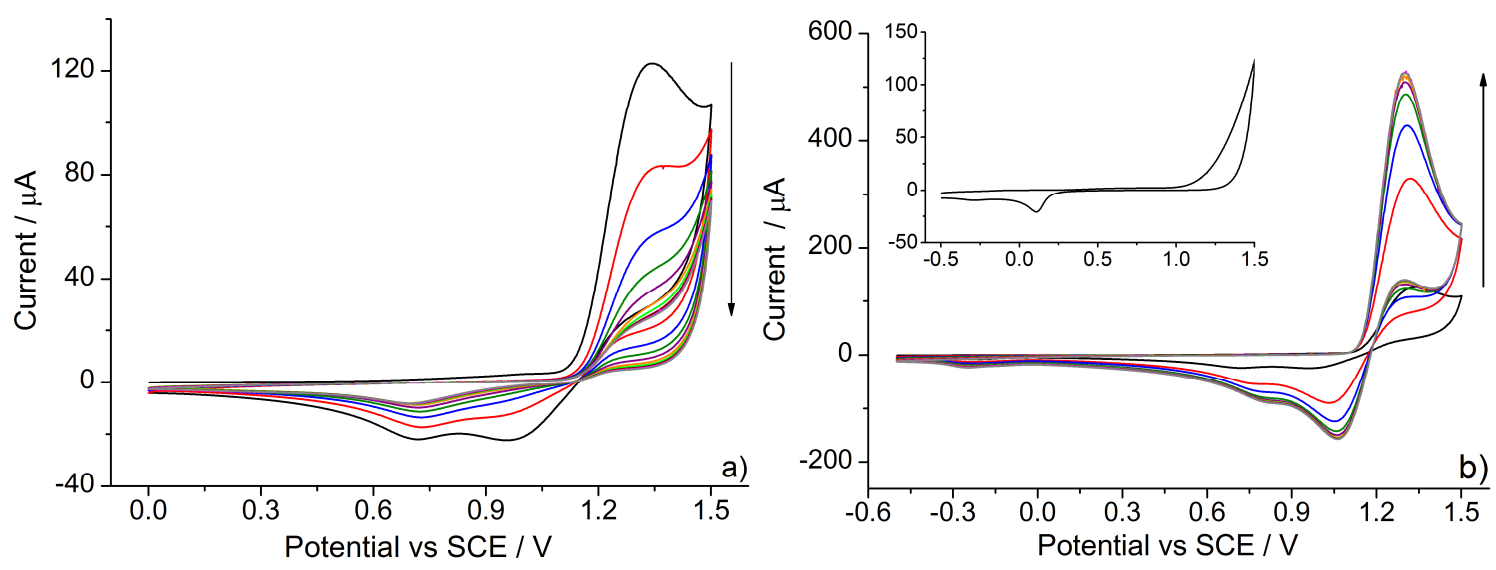

Fig. 2 Multiple successive cyclic voltammograms of $0.1 \mathrm{M} \mathrm{KCl}$ in $0.5 \mathrm{M} \mathrm{KNO}_{3}$ on a Pt macroelectrode of $1^{\text {st }}$ scan (black), $2^{\text {nd }}$ scan (red), $3^{\text {rd }}$ scan (blue), $4^{\text {th }}$ scan (green), $5^{\text {th }}$ scan (purple), $6^{\text {th }}$ scan (orange), $7^{\text {th }}$ scan (light green), $8^{\text {th }}$ scan (red-brown), $9^{\text {th }}$ scan (magenta), and $10^{\text {th }}$ scan (grey). A) The potential was scanned between $0.0 \mathrm{~V}$ to $1.5 \mathrm{~V}$ (Vs. SCE) at scan rate of $50 \mathrm{mV} \mathrm{s}^{-1}$. B) The potential was scanned between $-0.5 \mathrm{~V}$ to $1.5 \mathrm{~V}$ (vs. SCE) at scan rate of $50 \mathrm{mVs}^{-1}$. The inset shows the cyclic voltammogram of a Pt macroelectrode in $0.1 \mathrm{M} \mathrm{KF}$. 
On scanning to $-0.5 \mathrm{~V}$ (vs SCE) a small reduction peak can be observed at ca. $-0.25 \mathrm{~V}$ (Figure 2

b). This peak likely relates to the reduction of any platinum oxide concomitantly formed during the chloride oxidation. ${ }^{37}$ To confirm that the reduction peak is not chloride related, a cyclic voltammogram of a Pt macroelectrode in $0.1 \mathrm{M} \mathrm{KF}$ was recorded from -0.5 to $1.5 \mathrm{~V}$ vs. SCE at a scan rate of $50 \mathrm{mV} \mathrm{s}^{-1}$ (Fig. $2 \mathrm{~b}$ ) inset). Again a reduction peak is observed at $-0.25 \mathrm{~V}$, suggesting that the process is associated with the reduction of platinum oxide. Consequently, the increase in current of the peak at $c a .1 .3 \mathrm{~V}$, as shown in Figure $2 \mathrm{~b}$, is therefore associated with the redox cycling of the platinum surface. This in-situ activation of the electrode will be a result of either the effective cleaning of organic species from the surface or may alternately relate to an associated change in the surface morphology of the electrode leading to an increase in the surface coverage of active sites.

Importantly, in Figure 2 two reduction waves are seen to be associated with the chloride oxidation process. Moreover, the relative peak heights of these two reductive signals vary with the magnitude of the forward oxidative feature. In order to further investigate the origin of the differing reductive peaks, the chloride oxidation process was studied at a platinum nanoparticle modified glassy carbon electrode. The use of this platinum nanoparticle modified electrode enabled the surface coverage of the platinum, and hence the number of active sites for chloride oxidation, to be more readily controlled.

Modification of the glassy carbon electrode was achieved via drop casting $4 \mu \mathrm{L}$ of variable concentrations (16-120 pM, $14-111 \%$ surface coverage) of citrate-capped platinum nanoparticles (radius $=25 \mathrm{~nm}$ ) on to the carbon surface. The solvent was allowed to evaporate prior to submersion of the electrode into an electrochemical cell containing $0.1 \mathrm{M} \mathrm{KCl}$ and $0.5 \mathrm{M} \mathrm{KNO}_{3}$. In the absence of nanoparticles on the electrode surface no oxidative or reductive features are observed. However, as shown in Figure 3 in the presence of the platinum nanoparticles, an oxidative wave analogous to that observed for the macro electrode is recorded. Again this peak corresponds to the chloride oxidation, however notably the recorded peak currents are significantly below the diffusion limit. Using equation 3 and the previously measured diffusion coefficient, the diffusion limited reaction is 
expected to give a peak current of $523 \mu \mathrm{A}$. Moreover, first, the magnitude of the forward voltammetric wave scales with the surface coverage of the nanoparticles. Second, repeated voltammetric cycling does not result in the attainment of a diffusion limited response (as shown in Figure $\mathrm{S} 3$ in the $\mathrm{SI})$.

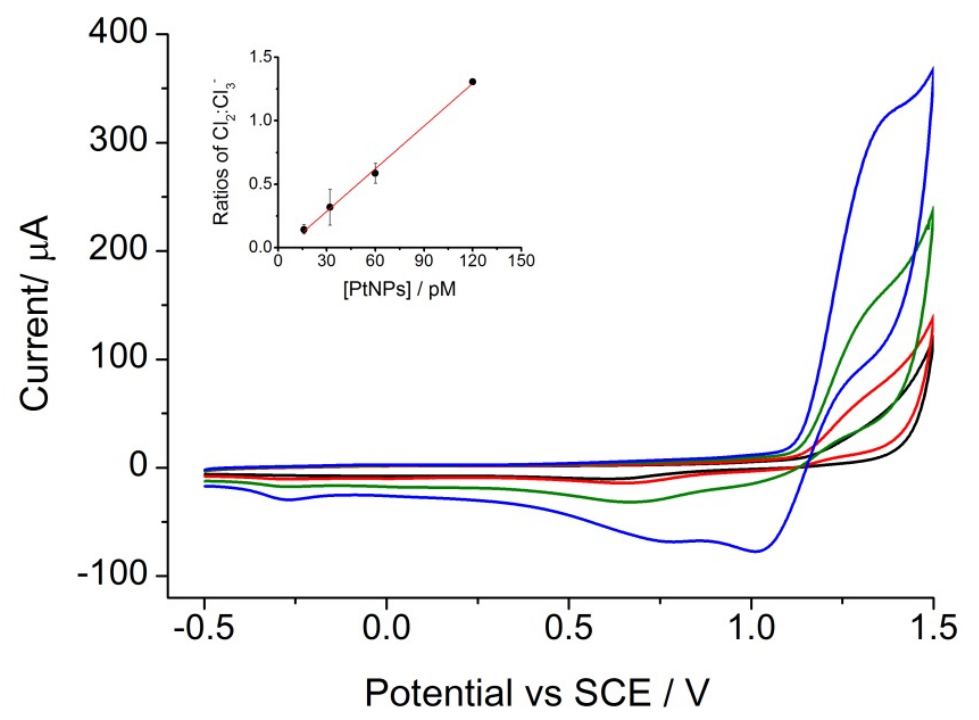

Fig. 3 Cyclic voltammogram of different surface coverages of dropcast Pt nanoparticles onto a glassy carbon electrode in $0.1 \mathrm{M} \mathrm{KCl}$ of $16 \mathrm{pM}$ PtNPs coverage (black, 14\% coverage), 32 pM PtNPs coverage (red, 28\% coverage), 60 pM PtNPs coverage (green, 56\% coverage), 120 pM PtNPs coverage (blue, $111 \%$ coverage). The potential was swept from - 0.5 to $1.5 \mathrm{~V}$ (vS. SCE) at scan rate of $50 \mathrm{mVs}^{-1}$. A plot of peak current ratios of $\mathrm{Cl}_{2}: \mathrm{Cl}_{3}^{-}$vs. concentration of PtNPs is shown in the inset. Error is the Standard Deviation.

The oxidation of chloride at the platinum surface proceeds via surface adsorbed intermediates. ${ }^{13}$ Consequently under conditions where the number of active sites available for the oxidation process is limited, then at high overpotentials the voltammetric response may become independent of the potential and a reaction limited steady state current may be observed..$^{38}$ In the present case of halide oxidation at the nanoparticulate surface, it is likely either recombination of two surface adsorbed halide radicals or desorption of the chlorine from the surface that kinetically limits the oxidative process. For the highest surface coverage of platinum nanoparticles studied in 
this work, a reaction limited current of $332 \mu \mathrm{A}$ is observed. Consequently, the average reaction limited current per nanoparticle can be estimated as approximately $1.1 \mathrm{pA}$. Due to the method of electrode modification used, this number likely represents a lower limit of the true reaction limited current per nanoparticle, ${ }^{39}$ since it is assumed that all nanoparticles drop cast are active and electrically connected to the glassy carbon substrate. The process of dropcasting has been reported to result in incomplete stripping, due to agglomeration of the NPs, therefore resulting in a lowerthan-expected current. ${ }^{40-42}$ Although the agglomeration may result in electrode heterogeneity, the surface coverage is sufficiently high to ensure that the diffusion layers of adjacent particles or agglomerates overlap almost entirely, ${ }^{43}$ allowing the dropcast to be considered effectively as a continuous diffusion layer. An alternative, considering the surface as a partially-blocked electrode, would require significantly larger areas of unblocked electrode to be present.

Beyond the magnitude of the forward wave varying as a function of the surface coverage of the nanoparticles, it can also be seen from Figure 3 that the relative ratios of the reductive peak currents at $1.0 \mathrm{~V}$ and $0.7 \mathrm{~V}$ are influenced by the surface coverage of the nanoparticles. For the higher surface coverages the reductive peak at $1 \mathrm{~V}$ is the dominant feature and for lower nanoparticle surface coverages only the reduction at $0.7 \mathrm{~V}$ is observed. As already discussed, due to the chloride oxidation being a surface reaction limited process, even at high overpotentials the surface concentration of chloride will be non-zero. Consequently, further reaction between the electrochemically formed chlorine, $\mathrm{Cl}_{2}$, and the excess chloride is possible. The formation of the trichloride anion occurs by the following reaction:

$$
\mathrm{Cl}_{2}+\mathrm{Cl}^{-} \leftrightarrows \mathrm{Cl}_{3}^{-}
$$

The formation constant for this process in water has been reported to be $K=0.177 \mathrm{M}^{-1},{ }^{44}$ hence formation of the trichloride anion species is relatively unfavorable and requires large excesses of chloride to yield the formation of trichloride product. On the basis of the above reaction and the observed variation of the reductive peak currents as a function of the surface coverage of the 
nanoparticles the peak at $1 \mathrm{~V}$ is ascribed as relating to the reduction of the electrochemically formed chlorine, conversely the reductive peak at $0.7 \mathrm{~V}$ corresponds to the reduction of the formed trichloride. Hence, by varying the surface coverages of the nanoparticles the speciation of the formed chlorine can effectively be controlled. The inset of Figure 3 shows the measured ratios of the reductive peak currents as a function of the nanoparticle surface coverage (as expressed as the drop-cast nanoparticle concentration). This range represents a surface coverage of $14-111 \%$. At the highest concentrations, the surface coverage exceeds a monolayer of particles. The differences observed on the macro and nano scale as described above are not a result of any change in the chemistry, but rather the altered mass-transport regime that occurs on a nanoparticulate surface compared with bulk Pt and the number of active sites that are available for the chloride oxidation to take place on.

\section{Conclusions}

Chloride oxidation at platinum surface follows an inner-sphere reaction, whereby at low coverages of active sites the oxidation process can become limited by the surface reaction rate. Moreover, by altering the surface coverage of the nanoparticles the rate of chloride oxidation can be effectively controlled. Under conditions where the reaction limited current is markedly smaller than the diffusion limited reaction rate, then the speciation of the formed chlorine can be changed such that the chlorine reacts further with excess chloride to form trichloride. The presence of the trichloride is evidenced by the alteration of the voltammetric reductive currents as a function of the surface coverage of the nanoparticles. Hence, we demonstrate how the chlorine speciation may be controlled where at low surface coverages the ratio of peak currents of $\mathrm{Cl}_{2}: \mathrm{Cl}_{3}{ }^{-}$can be as low as 0.14 , conversely with the use of high nanoparticle surface coverages the ratio can be as high as 1.3.

\section{Acknowledgements}


PK gratefully acknowledges the Development and Promotion of Science and Technology Talents Project (DPST) funded by the Royal Thai Government. EELT thanks the Clarendon Fund and St John's College for funding. The research leading to these results has received partial funding from the European Research Council under the European Union's Seventh Framework Programme (FP/20072013)/ERC Grant Agreement no.(320403).

\section{References}

1. H. Taube, Electron Transfer Reactions of Complex lons in Solution, Academic Press, Florida, 1970.

2. A. J. Bard, J. Am. Chem. Soc., 2010, 132, 7559-7567.

3. Stephan M. Hubig, A. Rajendra Rathore, and J. K. Kochi, J. Am. Chem. Soc., 1999, 121, 617626.

4. Emma Sigfridsson, A. Mats H. M. Olsson, and U. Ryde, J. Phys. Chem. B, 2001, 105, 55465552.

5. S. Aime, E. Gianolio, E. Terreno, G. B. Giovenzana, R. Pagliarin, M. Sisti, G. Palmisano, M. Botta, M. P. Lowe, and D. Parker, J. Biol. Inorg. Chem., 5, 488-497.

6. S. Goldberg, Environ. Sci. Technol., 1998, 32, 2383-2388.

7. Xiao-Yan Chen, A. Xiaoping Yang, and B. J. Holliday, J. Am. Chem. Soc., 2008, 130, 1546-1567.

8. B. H. Solis and S. Hammes-Schiffer, Inorg. Chem., 2011, 50, 11252-11262.

9. N. Elgrishi, B. D. McCarthy, E. S. Rountree, and J. L. Dempsey, ACS Catal., 2016, 6, 3644-3659.

10. N. Ramaswamy and S. Mukerjee, J. Phys. Chem. C, 2011, 115, 18015-18026.

11. K. Kumar, F. P. Rotzinger, and J. F. Endicott, J. Am. Chem. Soc., 2002, 105, 7064-7074.

12. K. L. Guyer and M. J. Weaver, Inorg. Chem., 1984, 23, 1664-1670.

13. W. R. Macdonald DD, Mckubre MC, Bockris JO, Conway BE, Modern Aspects of Electrochemistry, vol. 14., Plenum Press, New York, 1982.

14. and H. W. Chang, F. T., Z. Phys. Chem A, 1935, 172, 448.

15. A. Frumkin and G. Tedoradse, Zeitschrift für Elektrochemie, Berichte der Bunsengesellschaft für Phys. Chemie, 1958, 62, 251-256.

16. T. Dickinson, R. Greef, and L. Wynne-Jones, Electrochim. Acta, 1969, 14, 467-489.

17. T. Yokoyama and M. Enyo, J. Electroanal. Chem., 1982, 136, 185-190.

18. B. E. Conway and D. M. Novak, J. Electroanal. Chem., 1979, 99, 133-156.

19. B. E. Conway and G. Ping, J. Chem. Soc. Faraday Trans., 1990, 86, 923-930.

20. B. E. Conway and G. Ping, J. Chem. Soc. Faraday Trans., 1991, 87, 2705-2714.

21. D. M. Novak and B. E. Conway, J. Chem. Soc. Faraday Trans. 1 Phys. Chem. Condens. Phases, 1981, 77, 2341-2359.

22. X. Dai and R. G. Compton, Analyst, 2006, 131, 516-521.

23. R. Abu-Reziq, D. Wang, M. Post, and H. Alper, Adv. Synth. Catal., 2007, 349, 2145-2150. 
24. D. Zhai, B. Liu, Y. Shi, L. Pan, Y. Wang, W. Li, R. Zhang, and G. Yu, ACS Nano, 2013, 7, 35403546.

25. T. R. Ralph and M. P. Hogarth, Platin. Met. Rev., 2002, 46, 3-14.

26. Y.-J. Wang, D. P. Wilkinson, and J. Zhang, Chem. Rev., 2011, 111, 7625-7651.

27. O. T. Holton and J. W. Stevenson, Platin. Met. Rev., 2013, 57, 259-271.

28. I. Bar-On, R. Kirchain, and R. Roth, J. Power Sources, 2002, 109, 71-75.

29. D. A. Notter, K. Kouravelou, T. Karachalios, M. K. Daletou, and N. T. Haberland, Energy Environ. Sci., 2015, 8, 1969-1985.

30. W. Liu, D. Wang, Y. Duan, Y. Zhang, and F. Bian, Tetrahedron Lett., 2015, 56, 1784-1789.

31. A. J. Moreira, S. Lopera, N. Ordonez, and R. D. Mansano, J. Phys. Conf. Ser., 2012, 370.

32. K. Matsuoka, S. Sakamoto, K. Nakato, A. Hamada, and Y. Itoh, J. Power Sources, 2008, 179, 560-565.

33. A. P. Yadav, A. Nishikata, and T. Tsuru, Electrochim. Acta, 2007, 52, 7444-7452.

34. A. S. Barnes, I. Streeter, and R. G. Compton, J. Electroanal. Chem., 2008, 623, 129-133.

35. E. Kätelhön, C. Batchelor-McAuley, and R. G. Compton, J. Phys. Chem. C, 2015, 119, 2320323210.

36. R. C. Weast, S. Selby, and C. Hodgman, CRC handbook of chemistry and physics, Cleveland, Ohio, 46th edn., 1965.

37. V. I. Birss, M. Chang, and J. Segal, J. Electroanal. Chem., 1993, 355, 181-191.

38. K. J. Vetter, Electrochemical Kinetics: Theoretical Aspects, Academic Press, New York, 1967.

39. X. Jiao, C. Lin, N. P. Young, C. Batchelor-McAuley, and R. G. Compton, J. Phys. Chem. C, 2016, 120, 13148-13158.

40. S. J. Cloake, H. S. Toh, P. T. Lee, C. Salter, C. Johnston, and R. G. Compton, Chem. Open, 2015, 4, 22-26.

41. H. Toh, K. Jurkschat, and R. Compton, Chem. - A Eur. J., 2015, 21, 2998-3004.

42. H. S. Toh, C. Batchelor-McAuley, K. Tschulik, M. Uhlemann, A. Crossley, and R. G. Compton, Nanoscale, 2013, 5, 4884-4893.

43. N. Godino, X. Borrisé, F. X. Muñoz, F. J. del Campo, and R. G. Compton, J. Phys. Chem. C, 2009, 113, 11119-11125.

44. E. A. M. L.G. Sillén, Stability Constants, The Chemical Society, London, 17th edn., 1964. 
Table of Contents:

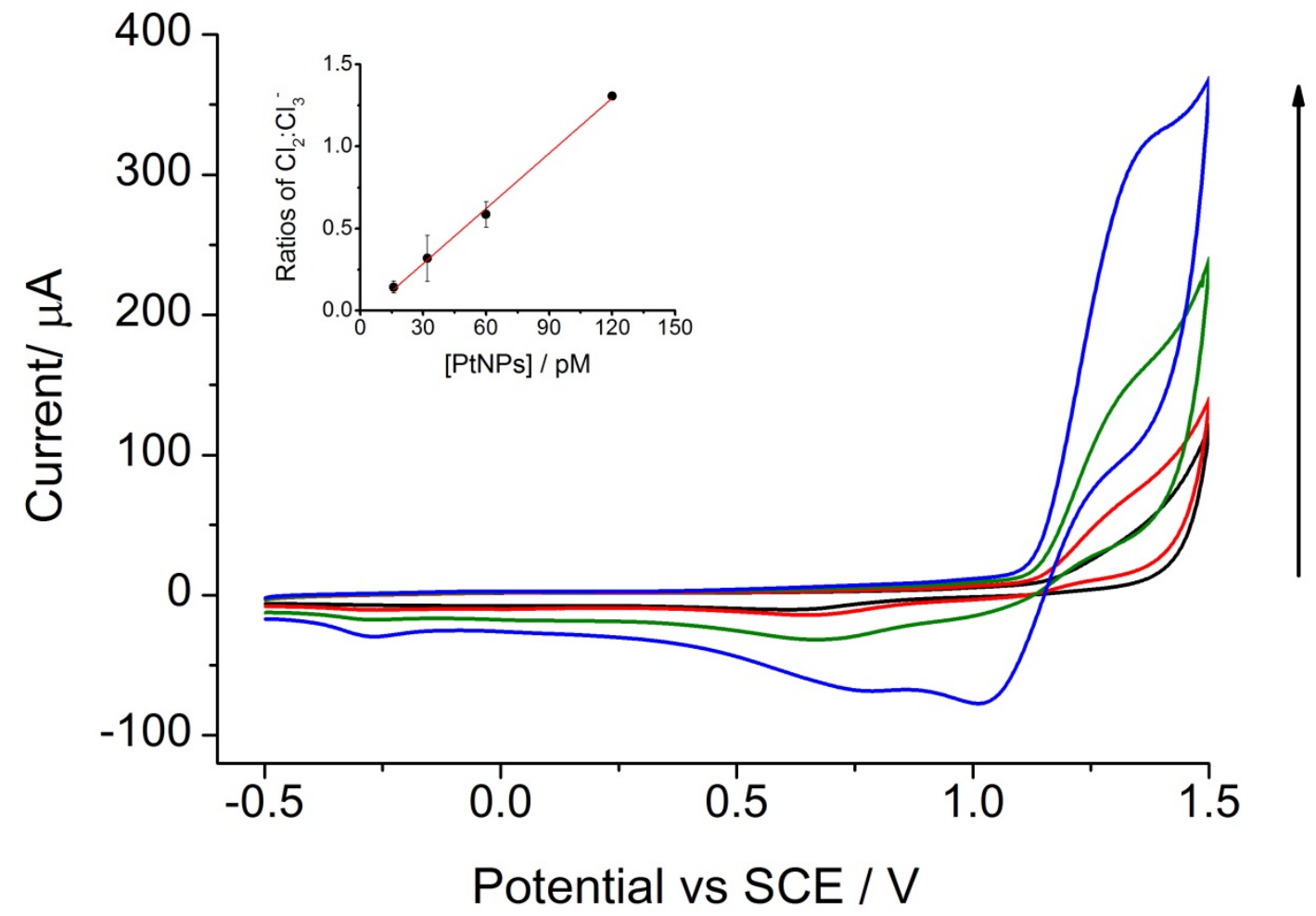

The surface coverage of Pt nanoparticles can control the speciation of electrochemically generated chlorine, altering the ratio of the products (chlorine or trichloride) with the number of available active sites.

Keywords: Chlorine, trichloride, platinum, nanoparticles 